\title{
TERMINOLOGIA EM CONTEXTOS INTEGRADORES: FUNCIONALIDADE E FUNDAMENTOS
}

\author{
Maria da Graça Krieger
}

\begin{abstract}
RESUMO: This paper aims to reflect on the role and relevance of terminology on the consolidation process of the economical, cultural and scientific integration in supra-regional contexts. The prominence given to terminology in its communicative and social dimension is contextualized in the reality of Mercosul. The theoretical and methodological fundamentals which support a terminographic project with an effective practical scope will also be emphasized. Additionaly, some investigation subjects, issues which are vital to the advance of a terminological theory based on communicational linguistics are pointed out.
\end{abstract}

PALAVRAS-CHAVE: terminologia, terminografia, funcionalidade, princípios teórico-metodológicos, funcionamento da linguagem, aplicações para o MERCOSUL

\section{Funcionalidade}

Cada vez mais, a terminologia assume relevância na e para a sociedade atual. Isto porque, em seus diferentes aspectos, vincula-se muito diretamente aos paradigmas de desenvolvimento econômico, tecnológico e cultural do mundo contemporâneo. Esses paradigmas, por sua vez, estão intimamente relacionados ao processo de globalização, ao acelerado desenvolvimento da ciência e da tecnologia e às novas tecnologias informáticas, com as implicações daí decorrentes, como as exigências de organização e divulgação da informação.

A globalização, impulsionando o incremento das transações comerciais entre nações, propiciou o surgimento dos atuais blocos econômicos, bem como de uma série de intercâmbios que ultrapassaram o âmbito comercial , expandindo-se para o mundo científico, tecnológico e cultural, como é o caso do Mercosul.

O alargamento das fronteiras, ampliando significativamente as relações internacionais, entre tantas repercussões, provocou efeitos no campo das línguas quer de um ponto de vista geral, quer particular. Entre uma série de aspectos, importa aqui salientar que os idiomas dos países integrantes das novas regiões supranacionais passaram a entrar mais fortemente em contato, exigindo novas conferências lingüisticas. Nesse sentido, o Mercosul é, hoje, um bloco afetado por uma situação de bilingüismo em razão da coexistência do português brasileiro e do espanhol falados na América Latina.

O conhecimento comum dos respectivos idiomas nacionais é reconhecidamente um importante fator de integração e uma condição de viabilidade para a consolidação harmônica dos blocos supranacionais. Inclui-se também como mecanismo de integração, os dispositivos dos acordos internacionais que têm atribuído o mesmo estatuto de idioma oficial às línguas faladas nos países integrantes das novas conjunturas.

Se estes são papéis sociais atribuídos às línguas na nova ordem mundial que caracteriza o final deste milênio, paralelamente, o emprego de terminologias adequadas às diferentes situações de comunicação é também componente essencial do sucesso dos empreendimentos estabelecidos. Isto porque, como se sabe, as comunicações profissionais articulam-se ao modo de linguagens especializadas, as quais compreendem, em larga medida, seus termos técnicos. Estes, são assim instituídos por força de especificidades conceituais dos diferentes campos do conhecimento, tal como expressa o pensamento de Benveniste:

A constituição de uma terminologia própria marca, em toda ciência, o advento ou o desenvolvimento de uma conceitualização nova, assinalando, assim, um momento decisivo de sua história. Poder-se-ia mesmo dizer que a história particular de uma ciência se resume na de seus termos específicos. (BENVENISTE, 1989, p.252)

Maria da Graça Krieger é professora do Instituto de Letras da UFRGS

Organon, Porto Alegre, nº 26, 1998 
A consideração de Benveniste, ao salientar a dimensão cognitiva das terminologias nas atividades resultantes do avanço do conhecimento, atualiza, simultaneamente, a função expressiva do componente lexical temático dos sistemas lingüísticos. Assim, o conjunto das unidades lexicais temáticas que configura a terminologia da área não é apenas a representação de um sistema conceitual, mas também, constitui-se em forte recurso lingüístico de precisão conceitual. Isto deve-se, em larga medida, ao caráter dos termos especializados que têm, como ideais de expressão, a monorreferencialidade, a monossemia e ainda a exclusividade denominativa, ao modo das nomenclaturas científicas.

Muito embora o funcionamento da linguagem demonstre, com freqüência, o descompasso entre um modelo idealizado e a realidade das línguas, a utilização de terminologias consiste numa tentativa de fugir da polissemia e das ambigüidades, próprias do léxico comum. A precisão conceitual é sempre considerada como uma condição necessária a uma adequada transmissão de conhecimento; favorecendo, em consequiência, um eficiente processo comunicacional entre especialistas. A almejada busca de univocidade justifica, portanto, o uso recorrente das terminologias nas linguagens especializadas.

Razões dessa natureza fundamentam a afirmação de que:

Para os especialistas, a terminologia é o reflexo formal da organização conceitual de uma especialidade e um meio inevitável de expressão e de comunicação profissional (CABRÉ, 1993 p.37).

Se a dimensão comunicacional da terminologia foi, originalmente, compreendida a partir do universo das ciências, hoje constata-se que a presença de termos especializados não se resume mais a esse universo. No momento em que se compreende os léxicos temáticos como unidades lexicais a serviço de uma comunicação especializada, se é levado também a reconhecer que se encontram vocábulos que adquirem a funcionalidade e o estatuto terminológicos nas mais diferentes áreas do saber. Atualmente, alargam-se os campos de conhecimento técnico e tecnológico, ampliando-se, conseqüentemente, os domínios de fixação de vocabulários especializados. O crescimento exponencial do conhecimento responde, sobremaneira, pela intensa proliferação terminológica que consiste num traço sócio-cultural típico de nossa época.

Da mesma forma, a comunicação relativa a temas científicos e a componentes e processos tecnológicos difunde-se largamente no mundo contemporâneo, não se restringindo mais a ambientes fechados. Isso acontece não apenas porque a ciência é objeto de grande interesse das sociedades, como a mídia e as novas tecnologias da informação impulsionam essa ampla divulgação.

Todo esse conjunto de fatores resulta na larga circulação de terminologias, cuja organização e divulgação tornam-se suportes lingüísticos operacionais no processo de integração e de consolidação de blocos supranacionais.

Efetivamente, as linguagens de especialidade, na busca da precisão conceitual utilizam termos próprios, com os quais circunscrevem conceitos e transmitem conhecimentos específicos. Dessa forma, uma utilização adequada das terminologias, favorecendo a univocidade comunicacional, é condição de eficiência das comunicações especializadas. Hoje, pode-se dizer que muitos segmentos já compreenderam que a precisão conceitual é necessária para o assentamento de toda sorte de contratos e das múltiplas e variadas proposições de intercâmbio que se intensificam com a globalização.

Diante da funcionalidade operada pelos termos especializados na transmissão de conhecimentos e de tecnologias, justifica-se a necessidade de seu conhecimento e de sua divulgação para um contexto de integração como o Mercosul. Se isto é válido para a integração interna, também o é para a consolidação externa visada pelo Mercosul, mercado que já é uma realidade, embora ainda precise superar uma série de problemas para fazer circular suas mercadorias no plano internacional.

Conseqüentemente, facilitar as condições de comunicação é uma estratégia que se apóia no acesso a repertórios terminológicos plurilíngües e que privilegiam áreas de interesse das sociedades que se integram na busca de seu fortalecimento. Esses repertórios, independente de orientações normalizadoras ou não, por sua própria natureza, assumem um valor referencial no quadro de escolhas lingüísticas apropriadas aos diferentes propósitos comunicacionais. A necessidade de contar com obras de referência plurilíngües na busca quer de conceitos, quer de denominações terminológicas atinge uma extensa gama de interessados em razão de suas atividades profissionais.

$\mathrm{O}$ interesse não se restringe mais aos especialistas que, como usuários diretos, sempre compreenderam a necessidade de dominar as terminologias de suas áreas de competência. Entre os usuários indiretos da terminologia, destacam-se os tradutores, intérpretes, documentalistas, os redatores técnicos, lexicógrafos e terminógrafos, estudantes universitários, entre outras categorias de profissionais que se envolvem com a linguagem.

Igualmente, avança o interesse dos comunicadores pelos termos técnicos, pois a ciência hoje é objeto de larga divulgação. Tanto que, se houve um tempo em que se postulava que o conteúdo das linguagens especializadas era de uso restrito aos profissionais da área, mas como, atualmente, a ciência e a tecnologia tornaram-se objetos cotidianos de notícia, nessa medida, também de interesse de público não especializado.

Mais ainda, a sociedade atual sofre o impacto da acelerada produção do conhecimentos, traduzido pelas mais variadas inovações tecnológicas que afetam seu cotidiano. De certo modo vive-se um processo de alfabetização técnico-científíco. Conseqüentemente amplia-se o contato e o interesse pelas terminologias, mesmo com os processos de vulgarização que atingem as novas necessidades comunicacionais. Do cruzamento dessas realidades, resulta a coexistência da vulgarização dos termos científicos e técnicos com o processo de terminologização de unidades lexicais da língua comum.

Organon, Porto Alegre, ํㅜ 26, 1998 
Em síntese, a existência e a circulação de terminologias em múltiplos e distintos universos de conhecimento é um testemunho de que os termos especializados assumem a grande função de promover e facilitar a transferência de conhecimentos, operados por meio quer das comunicações diretas entre especialistas, quer através das mediações comunicativas, como é o caso da mídia.

Em contrapartida, as exigências da mundialização estão fazendo com que os protagonistas dos processos de alargamento de fronteiras passem a perceber o importante papel dos termos técnico-científicos para uma comunicação mais eficiente, uma adequada transferência de tecnologia e um correto estabelecimento de contratos comerciais entre outras ações de cooperação.

A constatação da funcionalidade dos léxicos temáticos no mundo globalizado, está fazendo também com que alguns organismos governamentais e mesmo algumas empresas estejam buscando administrar os usos terminológicos. Estas, em primeiro plano, visam a um manejo padronizado dos termos dentro de um campo específico. Tal padronização relaciona-se à idéia de eficiência e de qualidade nos chamados setores produtivos, por otimizar o processo de comunicação nas empresas. Assim, do ponto de vista econômico e comercial, o uso padronizado das terminologias passou a ser reconhecido como um fator que amplia as condições de competitividade.

O conjunto das razões anteriormente apresentadas evidenciam que o Mercosul, no intuito de alcançar os propósitos pretendidos, necessita criar as condições necessárias ao acesso comum das terminologias. Isso significa a urgência de organizá-las em nossas línguas e de divulgá-las por meio da produção de instrumentos terminológicos bilíngües, contemplando o espanhol e o português aqui falados.

A necessidade intensifica-se diante da quase total inexistência de obras de referência técnico-científicas, elaboradas no português do Brasil e no espanhol dos países da América Latina, línguas que atualmente diferem, em muito, das faladas em Portugal e na Espanha.

Em suma, dotar o Mercosul de instrumentos terminográficos compreende criar as condições adequadas para o trabalho de produção de glossários, dicionários técnico-científicos, incluindo-se, obrigatoriamente, a constituição de um Banco de Dados Terminológicos. Este é um instrumento fundamental que permite recuperar a informação mais agilmente e que pode contar com os recursos trazidos pelas novas tecnologias da informação ${ }^{1}$. Tal aparelhamento é um investimento necessário ao desenvolvimento da terminologia, consistindo numa forma de divulgá-la de modo mais atualizado e operacional.

Por outro lado, criar as condições para recuperar e divulgar a informação, significa também facilitar o acesso ao potencial produtivo e científico do Mercosul. A rigor, trata-se de uma forma de sobrevivência. Vale dizer, ou temos a informação organizada ou, então, as transações tenderão a continuar no sentido preferencial, até agora conhecido, restringindo as condições de competitividade. Destaca-se, nessa perspectiva, o valor estratégico da sistematização e divulgação das terminologias.

Essas preocupações dizem respeito à efetiva inserção do Mercosul no contexto internacional. Neste caso, é preciso pensar as condições de resposta de todo bloco do Cone Sul, que já é visto como um segmento econômico respeitável, mas que ainda precisa desenvolver uma série de ações políticas com vistas a sua consolidação no mercado internacional, como já referimos.

Diante disso, adquire relevância a inclusão do inglês, como língua veicular das produções terminográficas. Caso contrário, os instrumentos produzidos não auxiliarão a circulação internacional das mercadorias e das tecnologias, assim como dos conhecimentos aqui produzidos. É preciso, portanto, compatibilizar os equivalentes terminológicos não apenas no que concerne ao português e ao espanhol, mas também ao inglês, sem excluir outras línguas de países produtores de conhecimentos e produtos de ponta, com os quais há interesse de intercâmbio.

Todas essas ações, que valorizam a qualidade da comunicação, funcionam como coadjuvantes na busca de competitividade comercial, bem como no estabelecimento de toda sorte de intercâmbios que se incrementam tanto no plano interno dos macro contextos regionais, quanto no plano externo das relações internacionais mais amplas.

Sem dúvida, os diferentes papéis que cumprem as terminologias técnico-científicas nos processos de integração e sua relevância na ordem mundial ora vigente, evidenciam a urgência do trabalho sistemático de coleta e organização dos termos técnicos e científicos criados e utilizados no Mercosul.

A divulgação de nossas terminologias, mesmo com os neologismos e interferências que as afetam, e com o devido registro das variações que sofrem, constitui uma instrumentação social necessária a um consistente processo de integração para a sociedade do Cone Sul. A produção terminográfica, justapondo ainda adequadamente nossas línguas, é também expressão de soberania, pois expressão do potencial produtivo - comercial, científico, tecnológico e cultural - de nossos países.

Nesse mesmo sentido, Maria Teresa Cabré afirma que uma língua sem terminologia:

Não está apta para os usos especializados, tão importantes como indispensáveis na civilização de hoje. Uma língua sem terminologia própria não pode ser no mundo atual uma língua de cultura. (1999, p. 33)

\footnotetext{
${ }^{1}$ Veja-se a esse respeito o trabalho de Anna Maria Becker Maciel, neste mesmo número.
}

Organon, Porto Alegre, ํㅜ 26, 1998 
Fazer avançar o projeto terminológico deve, portanto, ser componente das políticas de desenvolvimento das regiões que alargaram suas fronteiras e que precisam responder a novas exigências de competência lingüistica e profissional para afirmar-se e consolidar seu projeto de integração e de inserção internacional.

Entretanto, o desenvolvimento desse projeto, para além de significar a valorização das terminologias, ou seja, o devido reconhecimento de sua funcionalidade, exige o equacionamento de uma série de questões relacionadas tanto à definição de uma política lingüística adequada à realidade da região, quanto aos princípios teórico-metodológicos que devem reger o empreendimento terminográfico. De certa forma, são dois ângulos de uma mesma problemática.

\section{Fundamentos}

Todo e qualquer projeto terminográfico necessita delinear um conjunto de aspectos pragmáticos adequados aos propósitos visados, estruturando-se de modo a atender às necessidades previstas. Trata-se, assim, de definir os propósitos norteadores do empreendimento com vistas ao alcance e à funcionalidade do trabalho de organização terminológica. Um princípio fundamental é, portanto, reconhecer que o desenvolvimento da terminologia requer um projeto adequado para cada contexto e situação particulares, não cabendo a simples adoção de soluções estabelecidas "a priori”, oriundas de realidades distintas.

Tendo em vista a integração interna e a consolidação do bloco no mercado internacional pretendidas pelo Mercosul, muitas definições preliminares já se evidenciam como superadas, tais como a tipificação dos usuários e as línguas de trabalho, entre outras perspectivas que envolvem, por exemplo, a seleção de áreas prioritárias para o tratamento terminográfico.

Este trabalho, limitado a seu caráter acadêmico, não tem por objetivo definir o projeto terminológico dos países signatários do Tratado de Assunção ${ }^{2}$. Entretanto, independente de certas definições específicas e necessárias à operacionalização de um empreendimento terminológico de porte que, via de regra é da competência de organismos oficiais, tal como ocorre no Mercosul, há uma série de problemas teóricos e metodológicos que enfrentam aqueles que aceitam o desafio de trabalhar com terminografia.

Esta é um área que, ao contrário do que se possa pensar, não se resume a uma atividade compilatória. A organização de repertórios terminológicos, tanto sob a forma de glossários, dicionários, quanto de bancos de conhecimentos terminológicos, é uma prática que não pode prescindir da reflexão sobre o funcionamento da linguagem e de seus elementos constitutivos, posto que as terminologias são componentes naturais dos sistemas lingüísticos, sofrendo todos os efeitos da realização sistêmica e pragmática das comunicações em língua natural.

Nesse sentido, cabe reiterar que os fundamentos teórico-metodológicos consistem em marcos determinantes das formas de tratamento dos léxicos especializados. Aos aspectos pragmáticos, que contribuem para a definição dos propósitos comunicacionais e do formato dos instrumentos, somam-se as posições relativas às concepções teóricas norteadoras dos produtos terminológicos. De uma forma ou de outra, a configuração da produção terminográfica reflete posições distintas acerca dos modos de tratamento das terminologias que, em grandes linhas, vão se definir à luz de princípios prescritivos ou descritivos.

Atualmente, no cenário da terminologia, enquanto campo de estudos sobre os léxicos temáticos, contracenam concepções distintas acerca da natureza e do funcionamento das unidades lexicais especializadas. Em decorrência, encontram-se orientações diferenciadas para as aplicações terminológicas.

No bojo desse antagonismo, situa-se o processo de reavaliação que esta área de conhecimento está sofrendo nos tempos atuais. Mais exatamente, nos anos 90, assiste-se a um profunda revisão crítica sobre os fundamentos teóricos e epistemológicos originais da terminologia que se alicerçam numa visão idealizada e normalizadora do componente lexical temático das línguas.

A revisão sistemática que está sofrendo a Teoria Geral da Terminologia, cujos princípios foram estabelecidas a partir dos trabalhos de Eugen Wüster em torno dos anos 30, está revertendo os parâmetros mentalistas e normalizadores dessa teoria fundadora em favor de uma teoria terminológica de base lingüístico-comunicativa ${ }^{3}$.

Entre os aspectos relevantes que envolvem essa revisão, cabe salientar o reconhecimento do descompasso existente entre teoria e prática terminológicas. O modelo idealizado de exclusividade denominativa e de monossemia tem se mostrado inoperante diante do real funcionamento da linguagem.

O exame dos discursos especializados está demonstrando que nem sempre há um só conceito, nem tampouco uma única denominação correspondente, mesmo no interior de uma mesma área de conhecimento. A idéia da

\footnotetext{
${ }^{2}$ Para coordenar o projeto de um Banco de Dados terminológicos para o Mercosul, foi constituída a Subcomissão de Terminologia que atua no marco da Reunião Especializada de Ciência e Tecnologia, formada por representantes oficiais dos países signatários do Tratado de Assunção.

${ }^{3}$ Os fundamentos dessa teoria estão explicitados no artigo "La terminología hoy: replanteamiento o diversificación", de Maria Teresa Cabré, Judit Freixa, Mercè Lorente e Carles Tebé.
} 
invariabilidade terminológica corresponde a crenças fundadas no princípio da universalidade da ciência, expressas no bojo de uma concepção positivista sobre a produção do conhecimento.

Entretanto, a realidade dos usos dos léxicos temáticos têm também demonstrado a impropriedade da crença no princípio da homogeneidade lingüística que desconsidera, entre outros fatores, a variação terminológica e as realizações sinonímicas de alguns termos em diferentes comunicações especializadas.

Esse quadro, por si só, justifica a importância de que as informações oferecidas, além de fidedignas, conformando instrumentos confiáveis, necessitam retratar a realidade lingüístico-conceitual das terminologias repertoriadas, para tornar a consulta operacional. Para tanto, a elaboração de uma obra de referência que atenda às necessidades do consulente previsto, deve pautar-se por uma criteriosa definição e seleção de dados terminológicos, entre outros componente de ordem textual e discursiva, com vistas à tipologia macro e microestrutural privilegiadas.

Contemplar a variação no tratamento da terminologia é um procedimento teórico-metodológico que qualifica os instrumentos terminográficos elaborados nessa ótica, uma vez que eles permitem situar o usuário no panorama da diversidade de realizações do termo. Esta diversidade, de diferentes naturezas - regionais, sociais, profissionais e diacrônicas -, entre outros aspectos, costuma ser abordada no plano intralingüístico, consubstanciando o enfoque variacionista propriamente dito. Entretanto, quando se trata de um contexto supranacional que envolve a correlação de dois idiomas, como o português e o espanhol, a diversidade de realizações necessita ser examinada também no plano interlingüístico.

O registro das terminologias, com a devida compatibilização das diversidades nos dois planos, intra e interlingüístico, possibilitará ao Mercosul dispor de uma terminografia bilíngüe sistematizada e de maior alcance pragmático.

Com o tratamento descritivo dos termos, produzem-se instrumentos que não elidem o pleno funcionamento natural das línguas trabalhadas, respeitando-se as formas de expressão próprias das comunidades que se agregaram num contexto maior. Da adoção do princípio de acolher a diversidade das realizações terminológicas nas duas línguas oficiais do Mercosul depende a unidade e o fortalecimento do projeto terminográfico dessa macrorregião.

Além da perspectiva estritamente terminográfica, uma posição que respeita e compatibiliza a diversidade das realizações terminológicas em todos os seus níveis, assume um papel político estratégico na consolidação das conjunturas suprarregionais, pois as línguas, componentes maiores de identidades nacionais, têm estruturas diferenciadas para expressarem a produção e a apreensão do conhecimento.

Tais estruturas, por sua vez, refletem realidades sócio-históricas particulares, considerando-se, sobretudo, que: A língua sendo a condição do pensamento, constitui uma passagem obrigatória da colocação no lugar dos necessários processos cognitivos e comunicativos. (GAUDIN, 1993, p. 120)

Por outro lado, o reconhecimento da importância da variação em terminologia contrapõe-se à ilusão do controle sobre o emprego dos vocabulários especializados. Entretanto, mesmo no seio das posições variacionistas pode ser definido algum mecanismo que venha a orientar as escolhas das comunidades lingüísticas. De toda forma, essas posições, de modo geral relacionadas à problemática da norma lingüística, só ganham legitimidade, quando definidas no âmbito das instâncias oficiais responsáveis pela concretização do projeto terminológico do Mercosul.

Não obstante a possibilidade de direcionamentos que um projeto terminográfico supranacional possa vir a estabelecer, as disposições não alcançarão a funcionalidade pretendida, se baseadas no artificialismo das proposições arbitrárias que negam e procuram apagar o real funcionamento da linguagem.

A história tem mostrado a inoperância dos modelos normalizadores, produzidos com o intuito de controle dos vocabulários. Mas a história também tem demonstrado que as obras de referência, mesmo indiretamente, cumprem um papel normalizador. É um papel intrínseco ao seu estatuto de poder, decorrente da legitimação do léxico repertoriado. Os dicionários de língua constituem a expressão maior desse inevitável processo indireto de orientar as escolhas linguiísticas, assumindo o papel de código normativo no seio das comunidades lingüísticas, posto que:

O consulente, na elaboração de suas comunicações formais, orienta-se e submete-se aos registros dicionarizados, pois o dicionário representa o espaço de legitimidade do léxico de uma língua. De fato, ao registrar novos sentidos, novos termos e expressões, filhos da criatividade expressiva do homem, o dicionário confere-lhes legitimidade , atribuindo-lhes o estatuto de verdadeira palavra da língua. (KRIEGER, 1993, p. 15)

Transposta para o universo das obras de referência especializadas essa situação não é diferente. Ao contrário, reafirma-se o papel social, político e estratégico dos instrumentos terminográficos na e para as sociedades que valorizam, e ao mesmo tempo, dependem do conhecimento e das inovações tecnológicas, bem como do incremento do comércio e da cooperação internacional. Sob esse prisma, a agenda de uma política lingüística para o Mercosul deve também contemplar o incentivo às condições de produção dos instrumentos terminográficos.

Reflexões e considerações dessa ordem estabelecem o inter-relacionamento da pesquisa pura e aplicada em terminologia. Com efeito, toda a revisão crítica que se sucede neste momento, junto aos delineamentos para uma nova teoria da terminologia de base lingüístico-comunicacional, representam, conseqüentemente, uma reversão das orientações para a complexa tarefa de elaborar instrumentos terminográficos.

Da mesma forma, o reconhecimento da dimensão lingüística dos termos, compreendendo seu funcionamento efetivo em contextos reais de ocorrência, ou seja, em textos, responde por repercussões metodológicas que afetam vários

Organon, Porto Alegre, ํㅜ 26, 1998 
aspectos constitutivos da produção de terminografia. De maneira indireta, a organização dos instrumentos referenciais temáticos multilíngüies atualiza a problemática referente à tradução, em função da seleção dos equivalentes. É o caso, no Mercosul, da compatibilização entre os registros do português, espanhol e ainda do inglês, quando este é adotado como língua veicular. Simultaneamente, os estudos sobre os neologismos integram o panorama coadjuvante do trabalho terminográfico.

No entanto, importa salientar os problemas e os impasses que envolvem a constituição dos repertórios terminológicos. Estes centram-se na identificação e seleção dos termos, bem como na constituição de suas respectivas definições, a interface constitutiva das terminologias. Conseqüentemente, pode-se dizer que o avanço da teoria da terminologia reside no desenvolvimento de temas específicos, apresentando resultados e orientações que auxiliarão a produzir instrumentos mais qualificados, tornando, com isso, a tarefa mais operacional e melhor fundamentada cientificamente.

Tais temas podem ser divididos entre os que se relacionam ao reconhecimento do estatuto, da constituição e do funcionamento das unidades lexicais uni ou polilexemáticas, bem como as fraseológicas especializadas, e os que abordam as questões conceituais ${ }^{4}$. São dois lados de uma mesma moeda, posto que a pertinência terminológica de uma unidade lexical equaciona-se pela sua dimensão semântica e pragmática, atualizadas nos contextos reais em que ocorrem: os textos e os discursos especializados. Justifica-se, nessa perspectiva, o papel fundamental dos enunciados definitórios para a apreensão dos sentidos terminológicos. Em contrapartida, uma adequada definição terminológica, com paradigmas constitutivos próprios, torna-se também componente qualificador das obras de referência especializada.

Tal como compreendemos, os propósitos qualitativos de toda produção terminográfica vincula-se a um princípio teórico-metodológico básico, qual seja, o de que os termos sofrem os efeitos da realidade sistêmica em que se inserem, bem como integram o funcionamento da linguagem com todas as implicações daí decorrentes.

Conseqüentemente, na busca do equacionamento da identidade e da constituição das terminologias, como na análise dos enunciados definidores, os fatores de ordem textual e discursiva passam a assumir um papel preponderante, ampliando o poder explicativo da teoria da terminologia. Com isso, cada vez mais se evidencia que o tratamento terminológico, além de não se resumir a uma prática compilatória ordenada pela frequiência do termo, também não pode permanecer conformado às limitações dos enfoques morfossintáticos sobre as terminologias.

Com efeito, a consideração pelos modos de funcionamento das unidades terminológicas vem oferecendo importantes contribuições teórico-metodológicas ao complexo trabalho terminográfico. Ao mesmo tempo, tal perspectiva consiste num significativo aporte para fazer avançar a teoria da terminologia de base lingüístico-comunicacional.

\section{Considerações finais}

A peculiaridade das terminologias, circunscrevendo conceituações nos mais diferentes campos do conhecimento científico e tecnológico, evidencia seu papel na constituição e transmissão dos saberes humanos. A essa funcionalidade primeira soma-se a importância social e política, e mesmo estratégica, da organização e divulgação das terminologias para os contextos de integração, como o Mercosul.

Favorecer as condições da comunicação especializada é uma forma de oferecer ferramentas confiáveis de trabalho aos tradutores, aos redatores de textos técnicos e científicos, aos documentalistas entre tantos outros profissionais, cujo trabalho diário se ressente da grande carência de produtos terminográficos que contemplem o português e o espanhol falados no Cone Sul.

Em realidade, os paradigmas do mundo globalizado está ampliando, cotidianamente, o quadro de usuários da terminologia. Em contrapartida, cresce a consciência da importância de conhecimento e do uso pontual dos vocabulários técnicos.

Estrategicamente, o acesso a repertórios terminológicos auxilia na competitividade comercial, bem como em toda sorte de intercâmbios estabelecidos por meio da comunicação especializada.

Como procuramos mostrar, muitas são as razões em favor do incremento das ações que possam fazer com que o Mercosul disponha dos instrumentos adequados para efetivar a comunicação internacional e consolidar sua posição no cenário internacional.

Não bastassem os fatores pragmáticos, a valorização dos empreendimentos terminológicos deve encontrar sua motivação na crença de que a organização e divulgação de nossas terminologias, mesmo com os empréstimos e os neologismos a que estão afetas, consiste em uma forma de revelar o potencial econômico, científico e cultural da conjuntura supra nacional em que se constitui o Mercosul.

Como complementaridade à dimensão comunicacional, social e política da terminologia, esta, enquanto campo de estudos lingüísticos vem avançando significativamente nos últimos tempos. Em decorrência, estão se estabelecendo novas bases epistemológicas, de cunho lingüístico-comunicacional. Com o devido reconhecimento dos componentes

\footnotetext{
${ }^{4} \mathrm{O}$ conjunto dos artigos que constituem este número inscreve-se dentro dessas temáticas.
}

Organon, Porto Alegre, № 26, 1998 
textuais e discursivos que integram o funcionamento das linguagens especializadas, esta teoria está contribuindo para a reversão dos princípios da tradicional teoria da terminologia.

Tal reversão responde também pela definição de novos fundamentos para a tarefa terminográfica que alcançará maior qualidade e legitimidade, ao contemplar a diversidade das realizações terminológicas dos países que buscaram seu fortalecimento através da integração. Por sua vez, o fortalecimento do projeto terminográfico do Cone Sul depende desse respeito às diferentes formas que as línguas encontram para expressar os objetos, processos e mecanismos constitutivos dos conhecimentos especializados.

A opção por uma orientação sócio-comunicativa da terminologia representa ainda a possibilidade de que os atores do processo de integração sintam-se efetivamente sujeitos desse paradigma que rege a vida das sociedades nos tempos atuais.

No respeito à diversidade, reside, portanto, a unidade de um eficiente projeto terminológico para o Mercosul, centrado nos saberes científicos, técnicos e tecnológicos de áreas de interesse para seus propósitos de integração interna e de consolidação no panorama mundial.

Esse projeto deve integrar a pauta de uma necessária política lingüística para a região, pois toda língua constitui um ponto crucial de identidade cultural e de valores de uma sociedade. Não seria, portanto, um exagero afirmar que a soberania dessa nossa grande fronteira está, em muito relacionada, às estratégias de valorização de seus produtos tecnológicos e culturais. E, sem dúvida, a língua especializada é hoje, simultaneamente, tecnologia e cultura.

\section{BIBLIOGRAFIA}

BENVENISTE, Émile. Problemas de Lingüística Geral II. Campinas, Pontes, 1989.

CABRÉ, M. Teresa. La terminología. Barcelona, Antártida, Ampúries, 1993.

. La terminología: representación y comunicación. Barcelona, Universitat Pompeu Fabra, 1999.

GAUDIN, François. Socioterminologie. Rouen, Université de Rouen, 1993.

KRIEGER, Maria da Graça. A obra e o fazer dicionarísticos. In: Cadernos do IL. Universidade Federal do Rio Grande do Sul, 1993. N.10 